\title{
TAMAN BACAAN MASYARAKAT SEBAGAI SARANA PENINGKATAN MINAT BACA DAN TULIS ANAK USIA SEKOLAH DI DESA SURUHAN LOR
}

\author{
Yulia Nugrahini \\ Universitas Bhinneka PGRI \\ yn.max88@gmail.com
}

\begin{abstract}
Abstrak
Salah satu upaya yang dapat digunakan sebagai sarana untuk meningkatkan kesadaran dan pengetahuan masyarakat adalah melalui kegiatan membaca. Pengembangan budaya baca merupakan program edukasi masyarakat yang bertujuan untuk membangun masyarakat yang berilmu dan terampil, yang salah satunya dapat dilaksanakan melalui Taman Bacaan Masyarakat (TBM). Kegiatan pengabdian kepada masyarakat ini secara khusus bertujuan untuk meningkatkan minat baca tulis anak usia sekolah di Desa Suruhan Lor, Kecamatan Bandung, Tulungagung, melalui inisiasi TBM. Metode yang digunakan dalam program ini adalah metode learning by doing(melakukan langsung kegiatan membaca dan menulis), dan praktek sebagai aspek untuk menginisiasi, mengelola, dan mengembangkan dengan cara pendekatan partisipatif. Kelompok sasaran dilatih untuk mengelola TBM. Pelatihan ini disusun berdasarkan jadwal yang telah ditentukan. Materi yang diberikan meliputi materi teori umum, materi penunjang dan praktek pengelolaan TBM, inisiasi TBM dan tata laksana TBM. Kegiatan bina lingkungan ini dilakukan selama 8 (delapan) bulan yang meliputi kegiatan persiapan hingga pelaporan. Diakhir kegiatan diharapkan melalui ketersediaan TBM di Desa Suruhan Lor minat baca tulis masyarakat khususnya yang masih usia sekolah dapat ditingkatkan dengan adanya kegiatan yang akan dikelola oleh staf atau pengelola TBM.
\end{abstract}

Kata kunci: TBM, minat membaca dan menulis, usia sekolah

\section{Abstract}

One of the efforts that can be used as a means of increasing public awareness and knowledge is through reading activities. The development of a reading culture is a community education program that aims to build a knowledgeable and skilled community, one of which can be implemented through Taman Bacaan Masyarakat (TBM). This community service activities specifically aims to increase the interest in reading and writing of school-age children in Suruhan Lor Village, Bandung District, Tulungagung, through the initiation of TBM. The method used in this program is the method of learning by doing (doing direct reading and writing activities), and practice as an aspect of initiating, managing, and developing by means of a participatory approach. The target group is trained to manage TBM. This training is arranged according to a predetermined schedule. The material provided includes general theory material, supporting material and TBM management practice, TBM initiation and TBM management. This community development activity is carried out for 8 (eight) months, covering activities from preparation to reporting. At the end of the activity, it is hoped that through the availability of TBM in Suruhan Lor Village, the interest in reading and writing of the community, especially those who are still school age, can be increased by having activities that will be managed by TBM staff or managers.

Keywords: TBM, interested in reading and writing, school age 


\section{PENDAHULUAN}

Dasar Pemikirian dari kegiatan Pengabdian kepada Masyarakat adalah pendidikan merupakan faktor penting untuk mengentaskan rakyat dari kebodohan, keterbelakangan dan kemiskinan. Pemerintah berkewajiban mencerdaskan kehidupan bangsa. Hak untuk mendapatkan pengajaran atau pendidikan dinyatakan dalam Undang- undang Dasar 1945 pasal 31 ayat 1 yang menetapkan bahwa setiap warga negara berhak untuk mendapatkan pengajaran. Sebagai bentuk usaha yang dapat dilakukan dan dapat di jadikan sebagai sarana untuk meningkatkan banyaknya wawasan dan ilmu pengetahuan warga masyarakat terhadap berbagai bidang ilmu pengetahuan adalah melalui kegiatan gemar dan suka membaca. Membaca sebagai salah satu bentuk hobi dan juga kegiatan penunjang yang dapat mendorong warga untuk melakukan kegiatan yang lainnya yaitu menulis. Tetapi kegiatan ini sangat sulit penerapannya kepada warga masyarakat karena mereka lebih membutuhkan mencari penghasilan sebagaiupaya memenuhi kebutuhan ekonomi.

Pengembangan budaya baca merupakan salah satu program pendidikan masyarakat yang bertujuan untuk membangun masyarakat yang memiliki pengetahuan, keterampilan, maju dan mandiri yang pelaksanaanya dapat diwujudkan melalui Taman Bacaaan Masyarakat (TBM) sebagai medianya. TBM adalah sebuah lembaga yang menyediakan bahan bacaan yang di butuhkan oleh masyarakat. Sebagai tempat penyelenggaraan pembinaan kemampuan membaca dan belajar, sekaligus sebagai tempat untuk mendapatkan informasi bagi masyarakat. Pengelola TBM adalah mereka yang memiliki dedikasi dan kemampuan teknis dalam mengelola dan melaksanakan layanan kepustakaan kepada masyarakat. Bahan pustaka adalah semua jenis bacaan dalam berbagai bentuk media. Bahan bacaan yang umum adalah dalam bentuk buku cetak tetapi tidak menutup kemungkinan bisa dalam bentuk media yang lain yaitu e-book yaitu buku yang dijadukan bentuk digitak yang bisa setiap saat dibaca tanpa perlu membawa buku. Jadi bisa dilakukan melalui gadget atau HP. Jadi di TBM juga bisa menyediakan e-book sebagai salah satu media yang disimpan di TBM.

Program TBM merupakan pembaharuan dari Taman Pustaka Rakyat yang didirikan oleh pendidikan masyarakat pada tahun lima puluhan. Program ini bertujuan untuk meningkatkan minat baca dan budaya baca masyarakat. Oleh karena itu keberadaan TBM sangat penting sebagai sarana belajar masyarakat untuk itu kemampuan, ketrampilan dan kinerja pengelola harus ditingkatkan sehingga dapat mengelola TBM sebagai mana mestinya. Kenyataan menunjukkan bahwa program TBM belum sepenuhnya berhasil direalisasikan sebagaimana yang diharapkan. Salah satu penyebabnya adalah kemampuan, keterampilan serta dana pendukung yang dimiliki oleh suatu lembaga belum memadai untuk menyediakan faslitas bahan bacaan dan ruang membaca yang sesuai dengan tingkat kebutuhan masyarakat.

Warga masyarakat di Desa Suruhan Lor Kecamatan Bandung Kabupaten Tulungagung mayoritas adalah masyarakat yang hidup dengan mengandalkan mata pencaharian sebagai buruh dan petani, Jika hari minggu, masyarakat tersebut menjual hasil pertanian dalam bentuk sayuran dan buah-buahan ke pasar yang berlokasi di pusat kecamatan yang terletak $+10 \mathrm{~km}$ dari tempat mereka tinggal. Sedangkan bagi masyarakat yang bermata pencaharian sebagai buruh pendapatan yang mereka peroleh sangat bergantung pada ada tidaknya pesanan material yang akan mereka muat. Dari tingkat pendapatan mereka yang rendah, ini juga mempengaruhi pada tingkat daya beli terutama kemampuan untuk membeli buku bacaan yang dapat menambah wawasan dan pengetahuan.

Dengan latar belakang masyarakat yang lebih mementingkan memenuhi kebutuhan ekonomi maka tim dari Universitas Bhinneka PGRI bermaksud untuk membentuk suatu rintisan Taman Bacaan Masyarakat (TBM) yang berlokasi di Desa Suruhan Lor Kecamatan Bandung, Kabupeten Tulungagung. Keberadaan TBM dimaksudkan untuk mendukung pembudayaan kegemaran membaca masyarakat khususnya anak usia sekolah dan akan berkolaborasi dengan tim KKN yang melakukan kegiatan dengan program yang lebih kurang sama tetapi mempunyai kegiatan yang lebih rinci. 
Tujuan dari kegiatan Pengabdian kepada Masyarakat yang ingin kami capai ada 3 yaitu : Yang pertama adalah kegiatan wajib dari salah satu Tridarma Dosen Tujuan yang kedua yang ingin kami capai adalah membantu permasalahan yang ada di desa sasaran PKM dengan kegiatan yang menunjang untuk mengatasi menyelesaikan permasalahan. Di Desa Suruhan Lor ini akan di bentuk TBM yang menunjang kegiatan belajar khususnya minat baca dan belajar. Selanjutnya yang ketiga adalah menumbuhkan kepercayaan masyarakat akan kemampuan dosen sebagai tenaga pengajar mahasiswa di Universitas Bhinneka PGRI Tulungagung, sehingga akan lebih mendekatkan Universitas Bhinneka PGRI Tulungagung kepada masyarakat sekaligus untuuk promosi kampus dalam menjaring mahassiswa baru.

Manfaat dari kegiatan Pengabdian kepada Masyarakat adalah meningkatkan minat belajar khusus nya membaca dan menulis anak-anak desa dengan menumbuhkan motivasi dalam bidang pendidikan untuk lebih semangat menuntut ilmu, sehingga dapat menaikkan derajat desa tersebut, serta memberikan masa depan yang terjamin bagi warga masyarakat desa Suruhan Lor.

\section{METODE PENGABDIAN KEPADA MASYARAKAT}

Metode pelaksanaan PKM untuk mendukung pelaksanaan program PKM internal terintegrasi KKN ini kegiatan-kegiatan yang akan dilakukan meliputi kegiatan sosialisasi/penyuluhan, pendidikan dan pelatihan, serta praktek manajemen TBM serta pendampingan dengan menggunakan metode partisipatif. Secara detail dapat dideskripsikan sebagai berikut.

a. Kegiatan sosialisasi/penyuluhan dimaksudkan untuk meningkatkan pengetahuan, keterampilan sikap dan perilaku masyarakat sasaran dalam kaitannya dengan TBM, tujuan dan fungsi, serta dampak keberadaannya di tengah-tengah masyarakat. Pendekatan yang akan diadopsi berupa pembelajaran orang dewasa.

b. Pendidikan dan pelatihan manajemen TBM, dimaksudkan agar pengelola TBM nantinya dapat mengelola TBM dengan tatakelola yang baik, memiliki struktur organisasi yang jelas, memiliki visi dan misi, memiliki job deskripsi yang jelas dan tentunya memiliki program yang jelas khususnya yang berhubungan dengan peningkatan minat baca masyarakat.

c. Praktek manajemen TBM. Hal ini akan menjadi sarana evaluasi terhadap indikator hasil dari pelatihan manajemen TBM. Dengan praktek secara langsung oleh mitra tentang pengelolaan TBM maka mitra akan dapat mengidentifikasi secara langsung kekurangan-kekurangan dalam pengelolaan TBM.

d. Pendampingan. Dimaksudkan untuk memantapkan keterampilan pengelola TBM dalam mengelola TBM dengan baik sehingga dapat dikembangkan seiring dengan bergantinya waktu. Pendampingan juga dilakukan dalam kaitannya untuk mengevaluasi peningkatan layanan yang diberikan oleh TBM kepada masyarakat sekitar.

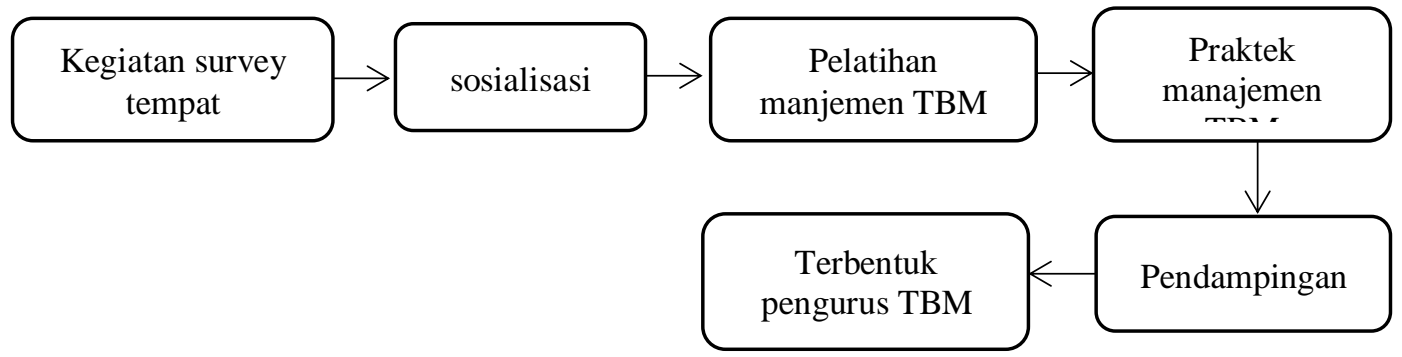

Gambar. Bagan Alir Pelaksanaan Pengabdian Kepada Masyarakat 


\section{HASIL DAN PEMBAHASAN}

1) Hasil

\section{a) Tahapan Penjajakan Lokasi}

Untuk mensukseskan kegiatan perintisan Taman Bacaaan Masyarakat di Desa Suruhan Lor Kecamatan Bandung, Kabupaten Tulungagung maka Tim PKM telah melakukan kegiatan penjajakan lokasi yang dianggap memadai dan representative untuk realisasi rintisan TBM. Dalam prosesnya, maka Tim PKM telah melakukan survey di beberapa lokasi di Desa Suruhan Lor Kecamatan Bandung, Kabupaten Tulungagung dan pada akhirnya ditentukanlah bahwa lokasi TBM ditetapkan akan dirintis di Balai Desa di Ruangan Sebelah sekolah PAUD yang lokasinya satu tempat dengan Balai Desa Suruhan Lor.

Dipilihnya Ruang PAUD di balai Desa Suruhan Lor sebagai lokasi rintisan TBM didasarkan atas beberapa pertimbangan diantaranya adalah belum tersedianya TBM di lokasi sekitar; terdapat 1 sekolah PAUD dan Sekolah Dasar Suruhan Lor di sekitar yang belum memiliki perpustakaan, keinginan para tokoh masyarakat sekitar bahwa mereka sangat setuju apabila disediakan sarana yang menjadi tempat anak-anak usia sekolah untuk membaca dan menambah ilmu pengetahuan. Khusysnya untuk usia Sekolah Dasar.

Tim melakukan survey lokasi untuk melakukan penetapan rumah salah satu masyarakat yang dijadikan tempat untuk posko perintisan TBM pada tanggal 6 sd 16 Oktober 2020, dalam kesempatan tersebut juga diidentifikasi para calon pengelola TBM yang berasal dari masyarakat sekitar.

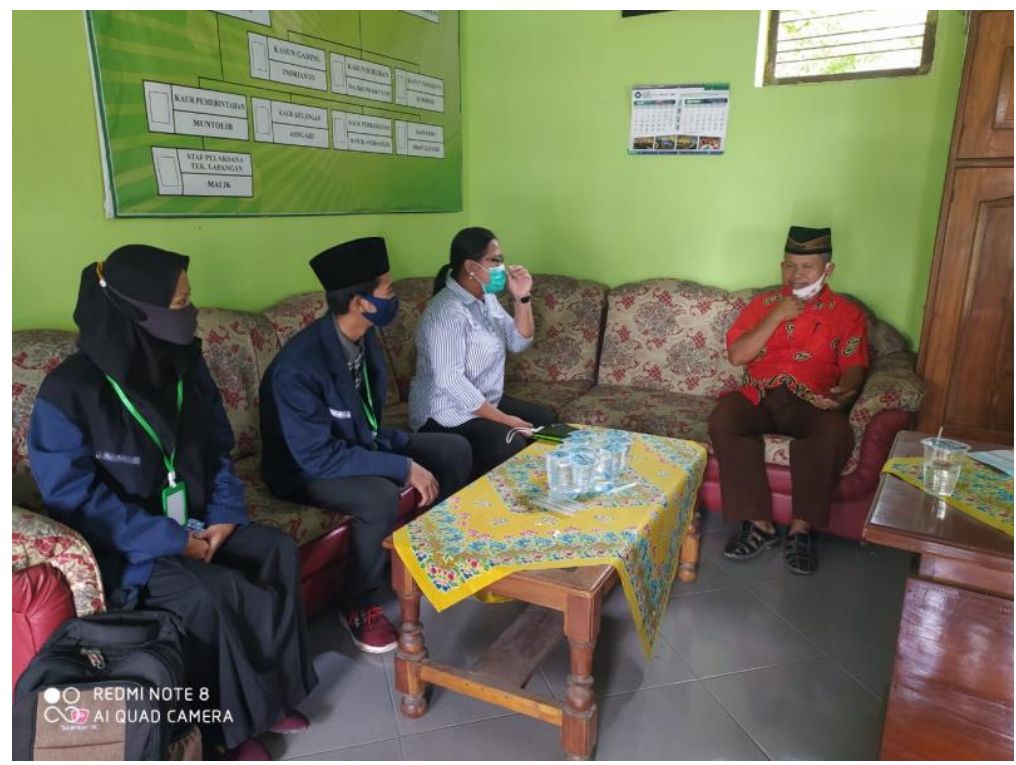

\section{b) Tahapan Pembentukan Pengelola TBM}

Setalah lokasi calon TBM ditetapkan selanjutnya dilakukan beberapa persiapan sebagai tindak lanjut dari kegiatan survey lokasi diantaranya meliputi identifikasi calon pengelola TBM, identifikasi sarana pendukung TBM, penyuluhan minat baca serta pembentukan organisasi TBM.

Dalam mempersiapkan lokasi dan sarana pendukung TBM, Tim PKM selanjutnya melakukan koordinasi dengan calon pengelola TBM dalam memenuhi kebutuhan sarana pendukung TBM seperti kebutuhan Rak buku, jenis buku, karpet, meja baca dan lain sebagainya.

Setelah dilakukan identifkasi terhadap kebutuhan, setahap demi setahap kebutuhan sarana penunjang dipenuhi dan disepakati ada yang dipenuhi oleh pihak Tim PKM dan ada yang ditangani langsung oleh calon pengelola TBM dengan tetap pendanaan bersumber dari tim PKM. 
Seperti halnya dalam pembuatan rak buku, disepakati untuk memberdayakan sumber daya sekitar yang membuatnya dan pendanaannya bersumber dari dana program serta bantuan dari dana desa.

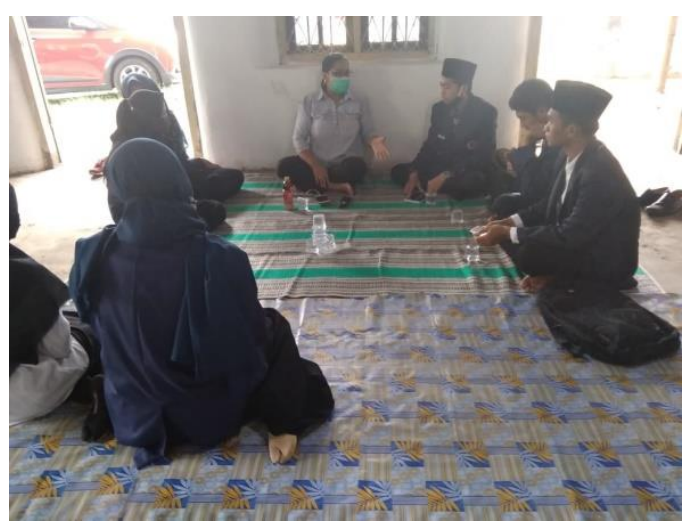

\section{c) Kegiatan pembentukan organisasi}

TBM dilakukan pada tanggal 8 Oktober 2020, sebelum dilakukan pembentukan organisasi TBM maka dalam beberapa rapat koordinasi antara Tim PKM dan pengelola TBM diidentifikasi dan disusun secara bersama beberapa kegiatan yang nantinya akan dilakukan secara bersama dan kolaboratif antara pengelola dan Tim PKM demi suksesnya rintisan TBM di Desa Suruhan Lor Kecamatan Bandung tersebut.

Dalam rangka mengelola TBM secara professional maka dibentuklah struktur organisasi pengelola TBM yang diberi nama "TBM Tiara" untuk menjalankan roda organisasi tersebut maka selanjutnya dibuatlah kesepakatan antar pengelola untuk membuat struktur pengelola TBM.

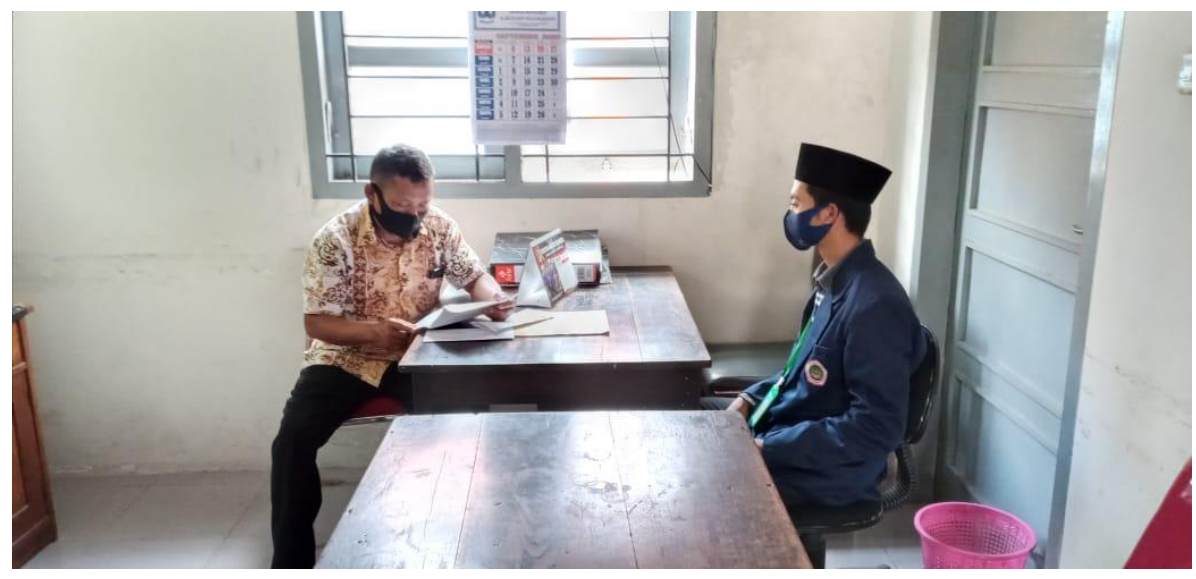

\section{d) Tahapan Implementasi Peningkatan Minat Baca dan Tulis Anak Usia Sekolah}

Setelah terbentuknya pengurus pengelola TBM Tiara, maka beberapa kegaiatan selanjutnya dirancang secara bersama antara pengelola TBM dan Tim PKM dan disepakati beberap kegiatan yang akan dilakukan di lokasi TBM diantaranya adalah

1. Membuka secara regular TBM bagi masyarakat desa Suruhan Lor secara luas khusunya bagi anak-anak usia sekolah.

2. Berdasarkan ketersediaan sumber daya pengelola, maka dibuka juga pembelajaran pengenalan bahasa Inggris kepada anak-anak usia sekolah untuk meningkatkan minat baca dan tulis anak. Disepakati pula untuk mengadakan kegiatan lomba-lomba anak Program PKM 
terintegrasi KKN yang terdiri dari lomba mewarnai, lomba menggambar,lomba baca puisi dan lomba cerdas cermat serta selingan acara game interaktif dengan anak-anak yang berada di TBM.
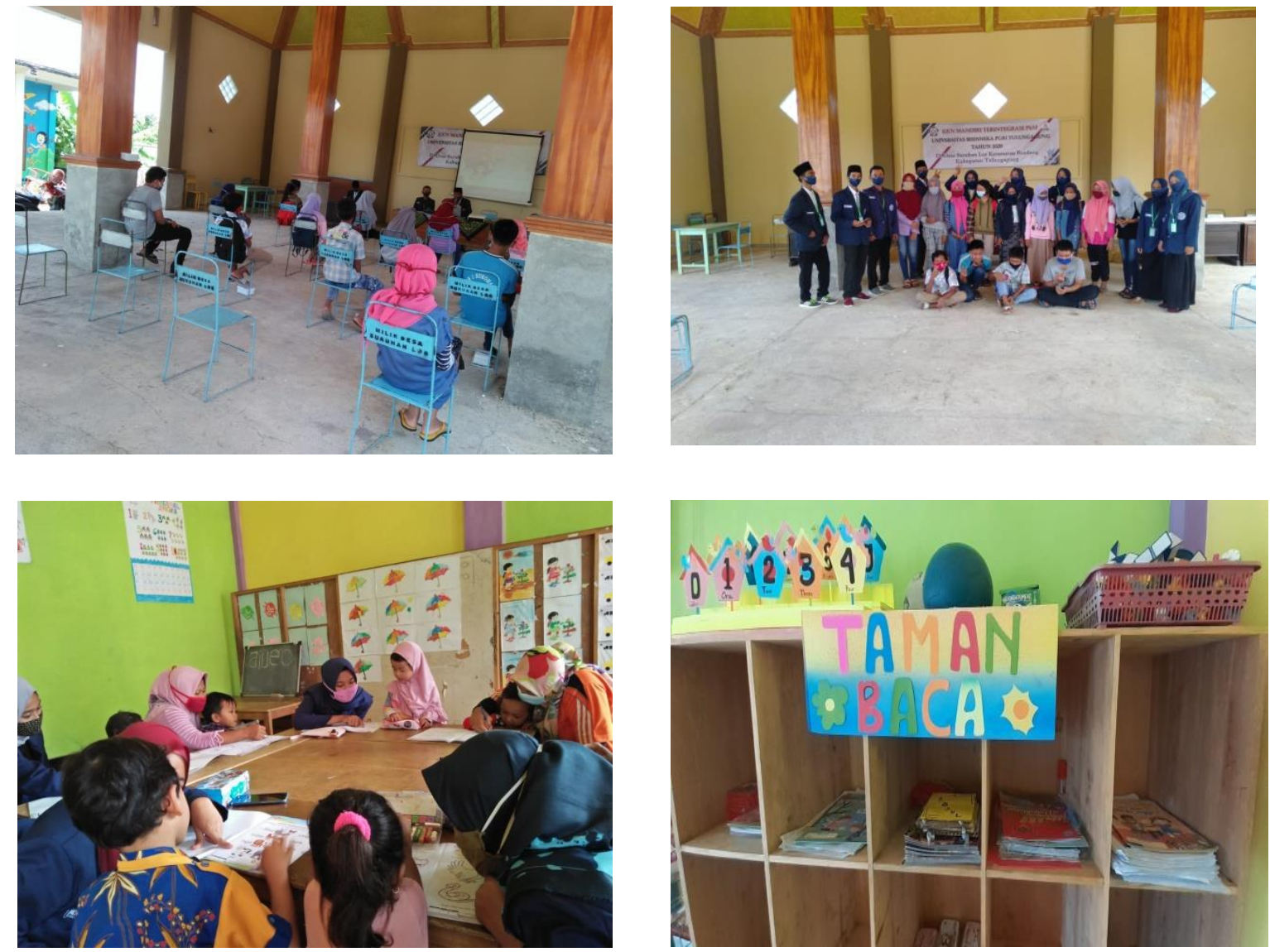

Hasil yang dicapai dalam kegiatan rintisan TBM ini meliputi:

1. Kelompok masyarakat sasaran telah mendapatkan penyuluhan dan pelatihan singkat pengelolaan TBM yang baik dari pihak Tim PKM.

2. Telah terbentuk satu Taman Bacaan masyarakat di Desa Suruhan Lor Kecamatan Bandung, Kabupaten Tulungagung dengan nama TBM Tiara.

3. Telah terbentuk pengelola TBM yang komposisi pengurusnya adalah masyarakat sekitar.

4. Telah terjalin kerjasama antara pengelola TBM dengan pemerintah daerah dalam upaya peningkatan pengelolaan dan layanan bacaan bagi masyarakat khususnya anak-anak usia sekolah melalui rintisan TBM yang ada.

5. Telah tersedia puluhan koleksi pustaka di TBM Tiara.

Telah dilaksanakan beberapa kegiatan peningkatan minat tulis dan baca anak melalui kegiatan pembukaan TBM secara regular dari pagi hingga malam hari serta melalui kegiatan lombalomba anak dengan kepanitian dari unsur pengelola TBM. 


\section{KESIMPULAN}

Berdasarkan hasil pelaksanaan kegiatan PKM ini, maka dapat diberikan beberapa kesimpulan sebagai berikut: (1) Kebutuhan terhadap sarana dan prasarana yang menyediakan koleksi bacaan sangatlah dibutuhkan di setiap wilayah yang masih terbelakang dari aspek pembangunannya. (2) Keberadaan TBM sangat membantu masyarakat dalam memenuhi kebutuhan mereka terhadap bacaan- bacaan untuk menambah wawasan dan ilmu pengetahuan. (3)Aktifitas dalam pengelolaan TBM tidak hanya terfokus pada penyediaan layanan koleksi pustaka, akan tetapi dapat berperan aktif dalam mencerdaskan masyarakat setempat dalam bentuk kegiatan- kegiatan seperti lomba-lomba yang ditujukan untuk meningkatkan motivasi mereka terhadap keterampilan membaca dan menulis serta semacam bimbingan belajar baca tulis.

\section{SARAN}

Saran yang bisa kami tuliskan dari kegiatan pengabdia kepada masyarakat adalah (1) Penerapan ini masih terbatas pada kelompok masyarakat yang berada di sekitar berdirinya TBM, sehingga masih perlu dilakukan upaya bagaiamna kegaitan pengabdian ini dapat dirasakan manfaatnya oleh mayoritas masyarakat dalam skala yang lebih luas di wilayah Desa Suruhan Lor Kecamatan Bandung, Kabupaten Tulungagung.(2)Keberadaan TBM ini kiranya dapat dijadikan contoh oleh Pemerintah setempat dalam upaya mencerdaskan masyarakat Tulungagung dengan mendirikan taman bacaan yang lainnya sampai pada tingkat yang terpencil sehingga bisa merata pada tiap masyarakat. 


\section{DAFTAR REFERENSI}

http://paudni.kemdikbud.go.id/bindikmas/tbm/?\#services

Kementerian Pendidikan dan Kebudayaan, 2014. Taman Bacaan Masyarakat (TBM Rintisan).

Kemendikbud.2013,Petunjuk Teknis Pengajuan, Penyaluran, dan Pengelolaan Bantuan Taman Bacaan Rintisan.Jakarta: Direktorat Pembinaan Pendidikan Masyarakat, DITJEN PAUDNI

Peraturan Pemerintah Republik Indonesia Nomor 24 Tahun 2014 Tentang Pelaksanaan UndangUndang Nomor 43 Tahun 2007 Tentang perpustakaan. Jakarta, Pemerintah Republik Indonesia.

Sutarno NS.2008,Membina Perpustakaan Desa. Jakarta, Sagung Seto 
